\title{
Alteração de práticas educativas com recurso ao computador Magalhães
}

\author{
Bruno Esteves, Manuel Meirinhos \\ Instituto Politécnico de Bragança- ESE
}

\begin{abstract}
Resumo
O advento da sociedade da informação traz consigo novos desafios e exigências à escola. A transformação das práticas educativas, com integração das TIC é, hoje, um desafio que se coloca a todos os professores. O projecto Computador Magalhães procurou, em Portugal, resolver parte do problema infraestrutural de acesso à tecnologia informática e a uma aprendizagem em suporte digital. Como resposta torna-se necessários que os professores adquiram formação técnico-pedagógica, desenvolvam os seus próprios recursos e os utilizem em contextos de aprendizagem, procurando inovar nas práticas, com 0 respectivo abandono das rotinas tradicionais. Este projecto pretende ser um contributo nesse sentido.

Palavras Chave: Plano Tecnológico da Educação, Integração das TIC
\end{abstract}

\section{Introdução}

As evoluções ocorridas nas últimas décadas ao nível da tecnologia têm definido a sociedade atual em que vivemos, onde muitos são aqueles que estudam as alterações que as TIC provocaram no nosso dia-a-dia, em relação à comunicação, interação e aprendizagem. Alguns autores chegam a comparar esta transformação tecnológica a momentos marcantes na história da humanidade, tais como a revolução agrícola, à descoberta da imprensa ou à revolução industrial. De facto, estamos perante um momento que modifica as condições da nossa existência al alterar o modo de acesso à informação, ao modo como comunicamos e à forma como nos relacionamos e aprendemos.

A Escola, como parte integrante e pilar da sociedade, não pode distanciar-se desta evolução tecnológica. Exige-se então à Escola uma constante adaptação ao contexto social e tecnológico que a envolve. Muitos países desenvolveram projetos neste sentido. São os projetos conhecidos por 1:1, ou seja um computador por aluno. Em termos gerais podemos definir esses projetos, mais ou menos como fenómenos de moda, que se propunham alfabetizar digitalmente a sociedade combatendo a infoexclusão e, fornecer a infraestrutura necessária para a aprendizagem em suporte digital. Foi para tirar vantagem educativa das infraestruturas fornecidas pelo projeto Magalhães (projeto 1:1 em Portugal) que se realizou este trabalho. Participaram cinco professores do primeiro Ciclo que trabalhavam em duas escolas do agrupamento de Miranda do Douro. Foram envolvidos um total de 68 alunos. O trabalho teve como objetivo principal a integração de atividades educativas multimédias utilizando o computador Magalhães, em contexto de sala de aula.

Neste artigo fazemos uma abordagem ao contexto de utilização das TIC em sala de aula, apresentamos os objetivos e as fases do projeto e respetiva avaliação. No final apresentamos uma breve reflexão.

\section{O contexto da utilização educativa das TIC}

Devemos estar conscientes que a introdução das TIC em contextos de aprendizagem, de forma inovadora, não é tarefa fácil, pois como refere Pedró (2010):

"Ainda que o acesso às novas tecnologias digitais nas escolas tenha aumentado significativamente nos últimos dez anos, sua adoção não se observou tão rápida e intensivamente quanto o esperado, apesar dos esforços políticos em promover e apoiar a inovações com base em tecnologia na escola.” (p.11)

O PTE (Plano Tecnológico Para a Educação), pretendeu ser um programa de modernização tecnológica das escolas portuguesas, desde o Ensino Básico até ao Ensino Superior, procurando interligar de forma integrada e coerente um esforço ímpar na infraestruturação tecnológica das escolas, na disponibilização de conteúdos e serviços em linha e no reforço das competências TIC de alunos, docentes e não docentes. Com este Programa, o Governo Português visou transformar as escolas portuguesas em espaços de interatividade, de partilha de informação e opinião sem barreiras, preparando os alunos enquanto parte integrante da sociedade do conhecimento para os desafios que esta lhes cria.

Segundo a Agência para o Conhecimento (2010), “o Plano Tecnológico da Educação envolve uma profunda modernização das escolas com a criação de modernas redes de comunicação nas escolas, o aumento drástico da largura de banda das ligações das escolas à Internet, o aumento do número de computadores com ligação à Internet disponíveis nas escolas, a disponibilização de conteúdos e serviços online e o reforço de competências em TIC de alunos e docentes.” (p. 8).

O Ministério da Educação, (Plano Tecnológico da Educação, 2007), define como objetivos para a modernização da Educação:

“Garantir o apetrechamento informático das Escola

Apoiar o desenvolvimento de conteúdos

Apostar na formação dos professores em TIC

Promover a generalização de portfolios de atividades em suporte digital

Fomentar o desenvolvimento e uso das TIC por cidadãos com necessidades especiais 
Identificar e divulgar exemplos de boas práticas

Promover o uso de open source, reforçar a segurança e a fiabilidade dos sistemas TIC.” (p. 2).

Estes pressupostos são a malha conceptual na qual o Plano Tecnológico da Educação se procurou desenvolver. Foi estruturado em três eixos temáticos de intervenção: tecnologia, conteúdos e formação. O eixo da tecnologia pretendeu dar resposta às barreiras em termos de infraestruturas e acessos, na qual foram definidas como áreas de intervenção os computadores, o equipamento de apoio, a conectividade, as redes de área local, os cartões de aluno, os sistemas de segurança eletrónicos e o apoio técnico às Escolas. Para tal, foram enquadrados e desenvolvidos os projetos Kit Tecnológico Escola, Internet de Banda Larga de Alta Velocidade, Internet nas Salas de Aula, e-escola, e-professores e e-oportunidades, e-escolinha, Cartão Eletrónico do Aluno, Escola Segura: Videovigilância e Alarmes, e Centro de Apoio Tecnológico às Escolas. O eixo dos conteúdos pretendeu alterar as práticas pedagógicas favorecendo o recurso a métodos de ensino mais interativos e construtivistas, conducentes a melhores níveis de eficiência nas Escolas. As suas áreas de intervenção são a produção e partilha de conteúdos, a produção e partilha de aplicações de gestão, a certificação de conteúdos e aplicações, a informatização de manuais escolares e o software open source. De forma a dar resposta foram desenvolvidos os projetos MaisEscola.pt, Portal das Escolas, Escola Simplex, Manuais Escolares Eletrónicos e Plataforma Eletrónica Integrada. O terceiro eixo, o eixo da formação, procurou dar resposta à falta de competências dos docentes ao nível das TIC, uma das principais causas para a escassa utilização da tecnologia nas Escolas.

É nestes três eixos (tecnologia, formação e conteúdos) que se desenvolveu o nosso projeto. Para a elaboração dos conteúdos optamos pela ferramenta EdiLim, que é uma ferramenta que segue a filosofia de livro multimédia. A ferramenta permite criar conteúdos educativos multimédia, baseada numa grande variedade de páginas com diferentes atividades interativas. É uma ferramenta composta por um editor de atividades (EdiLim), um visualizador (LIM) e um arquivo em formato XML (livro) que define as propriedades do livro e as distintas páginas que o compõem. Este software é adequado para crianças do ensino préescolar, $1^{\circ}$ ciclo e $2^{\circ}$ ciclo, e permite abordar qualquer área disciplinar destes níveis de ensino. Possui um ambiente gráfico agradável, as suas atividades são atrativas. Possui a vantagem de poder ser executado sem o instalar no computador, é portanto, um recurso fácil para o docente, uma vez que não precisa preparar os computadores dos alunos. A criação de atividades é realizada de forma simples e permite fazer avaliação dos exercícios, bem como, controlar os progressos dos alunos. Depois da exportação do livro, as atividades podem ser colocadas online ou em suporte local e resolvidas com recurso a um browser.

Neste programa podem ser criadas actividades diversificadas e desafiantes, baseadas no jogo com carácter lúdico-educativo. Pensamos ir assim de encontro às palavras de Berracoso et al (2009):

“A adaptação do software livre às caraterísticas dos alunos é um fator que pode favorecer a aquisição da aprendizagem significativa, contudo, os professores estão conscientes da necessidade de uma alteração metodológica que aproveite todas as potencialidades expressivas e comunicativas das tecnologias, incluindo a noção de jogo como elemento motivador.” (p. 120).

O suporte tecnológico utilizado foi fornecido pelo projeto Magalhães: o computador Magalhães. Conforme a Eurydice (2011), os professores reconhecem o valor das TIC na Educação, contudo encontram dificuldades na sua utilização em sala de aula e, por esta razão são poucos os que as utilizam. Provavelmente os professores não se sentem capacitados para a utilização das TIC em contextos de aprendizagem e, em consequência, para reverter esta situação, os professores deveriam ser formados para tal fim.

\section{Objetivos}

Foram definidos três objetivos essenciais para este projeto, e em cada um deles os seguintes objetivos específicos:

Caracterizar a Realidade Escolar face ao Computador Magalhães.

Desenvolver a aquisição de competências para a utilização do programa Edilim e do computador por parte dos professores dos professores participantes.

Integrar as atividades desenvolvidas em Edilim nas práticas de aprendizagem em sala de aula, utilizando como suporte o computador Magalhães.

Em relação a este último objetivo definimos como objetivos específicos:

- Verificar a aquisição de competências TIC por parte dos alunos;

- Verificar a motivação dos alunos na aprendizagem;

- Averiguar a autonomia dos professores na utilização das atividades educativas com 0 computador Magalhães em sala de aula.

Para a consecução destes objectivos, elaboramos um projecto baseado em 4 fases:

Fase 1- Conhecimento da realidade

Fase 2 - Formar os professores para a utilização das TIC em contexto educativo

Fase 3 - Implementação das TIC em contextos de aprendizagem

\section{Fases da investigação}

Para a consecução destes objetivos, elaboramos um projeto de trabalho baseado em 3 fases:

Fase 1- Conhecimento da realidade

Fase 2 - Formar os professores para a utilização das TIC em contexto educativo

Fase 3 - Implementação das TIC em contextos de aprendizagem 


\section{Fase1 - Conhecimento da realiadade}

Na Fase 1, pretendeu-se perceber a frequência com que o computador Magalhães é utilizado em contexto escolar e extraescolar na alteração das práticas tradicionais e, ainda, perceber qual o nível de formação dos professores para trabalhar com o computador em sala de aula. Foi também nesta fase que identificamos professores interessados em participar no projecto. Encontramos cinco professores que se disponibilizaram para participar no projeto. Verificamos que no contexto escolar onde esses professores lecionavam raramente era utilizado o computador Magalhães. Nas situações em que era utilizado, essa utilização centrava-se essencialmente na exploração de jogos (já instalados no computador) e na utilização de programas como o Word e o Paint.

O projeto de correu em algumas escolas do $1^{\circ}$ Ciclo do agrupamento de escolas de Mirando do Douro e participaram alunos dos vários anos de escolaridade, tal como é demostrado pela imagem 1 .

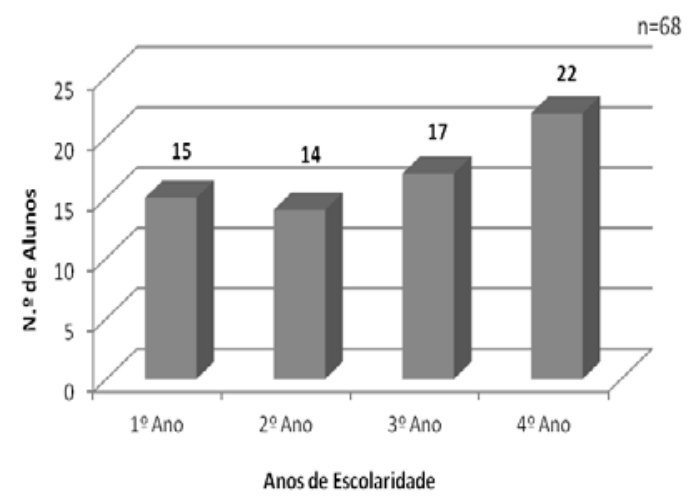

Imagem 1. Distribuição dos alunos intervenientes.

Os conhecimentos da realidade obtidos nesta fase permitiram-nos elaborar com mais exatidão as fases seguintes.

\section{Na fase 2 - Realização da formação}

A formação dos professores para a criação de atividades multimédia adequadas aos alunos do 1 ciclo ocorreu em duas modalidades: formação em grupo e formação individualizada.

\section{Formação em grupo}

Numa primeira fase foi dada formação neste programa, realizamos cinco sessões de aproximadamente duas horas cada. Estas sessões decorreram depois das aulas, da parte da tarde e todos os professores trabalharam nos seus computadores portáteis pessoais. Esta fase ocorreu durante dois meses.

Dos seis professores que participaram na formação dois revelaram mais dificuldade em lidar com o computador e com o programa Edilim. Apresentavam, no entanto, uma grande vontade de aprender.

\section{Formação individualizada}

Esta formação ocorreu depois da anterior e teve por finalidade orientar os professores na criação de atividades específicas para os seus alunos. Os professores já tinham identificado a área curricular e o tema específico para desenvolver e aplicar com as respetivas turmas em contexto ensino e aprendizagem. Teve a duração aproximada de dois meses, com várias sessões por professor, num total de 19 sessões e revelou-se verdadeiramente fulcral na criação de atividades.

\section{Fase 3 - Implementação das atividades desenvolvidas}

A fase 3 consistiu na implementação em sala de aula das atividades desenvolvidas pelos professores na fase anterior. Foram implementadas um total de 12 sessões em sala de aula, para abordagem aos conteúdos curriculares e utilizando o computador Magalhães. O investigador esteve presente nas 12 sessões.

Para a avaliação desta fase utilizamos o diário para registo de observações das sessões, questionários aos alunos e entrevistas aos professores.

- Desenvolvimento de competências TIC por parte dos alunos: os professores foram unânimes em considerar que os alunos desenvolveram competências em TIC com a utilização do computador Magalhães na sala de aula. Esse foi também um registo retirado do diário, pois bastante visível que a destreza dos alunos melhorava na utilização do computador e na exploração das atividades multimédia, à medida decorriam as sessões. Houve até professores que começaram a utilizar o Magalhães com os seus alunos para outras finalidades e que referiram essa aquisição de competências. A aquisição das competências com a utilização do computador está bem patente na entrevista dada por uma professora: " $\mathrm{O} 1^{\circ}$ ano escreve frases, mesmo a professora da turma, há dias me dizia: - como é que eles conseguem? Conseguem escrever frases, ir buscar uma imagem, colocá-la.... Muito mais autónomos, abrem o computador, fecham. Se eu mandar ir ao Word, "olhem que é o que tem o "W" azul", os de $1^{\circ}$ ano já sabem qual é, também trabalharam no Paint e no TuxPaint, mas adquiriram muitas competências.

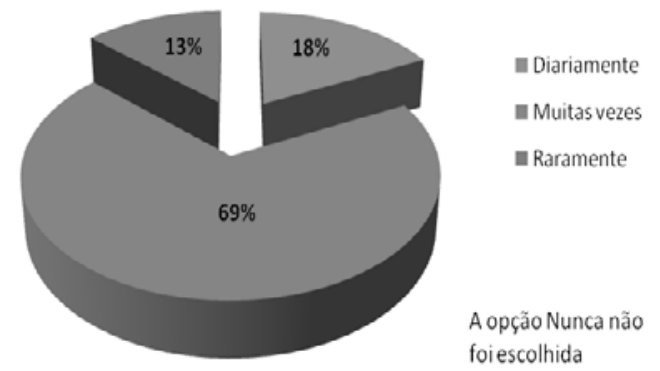

Imagem 2. Frequência semanal sobre a utilização do computador

Os alunos parecem também evidenciar o interesse pela utilização do Magalhães, a frequência de utilização semanal do computador, 69\% manifestaram 
vontade o utilizar muitas vezes, $18 \%$ diariamente e 13 \% raramente. A opção nunca, não selecionada pelos alunos.

\section{- Motivação dos alunos na aprendizagem}

Os professores foram unanimes em considerar que todos os alunos se sentiram mais interessados nas aulas onde se utilizavam as atividades multimédia no computador Magalhães.

O grau de interesse das aulas quando se utilizam as atividades multimédia aumenta bastante, conforme podemos verificar na imagem 2. O interesse aumentou muito para $88 \%$ dos alunos, aumentou algo para $9 \%$ e não aumentou para 3\%.

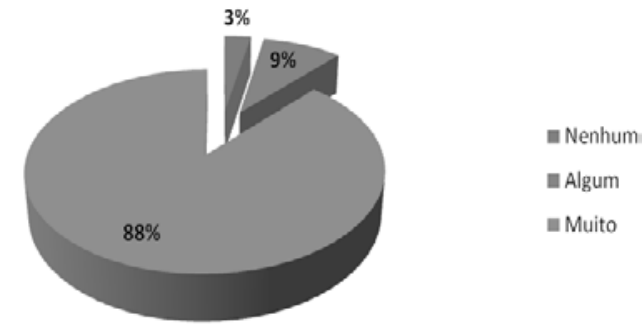

Imagem 3. Interesse dos alunos nas aulas com atividades multimédia.

Quando questionados sobre a sua motivação (imagem 3) a resposta foi muito semelhante ao interesse, uma vez que $88 \%$ indicam que se sentem mais motivados e apenas $12 \%$ igualmente motivados. Saliente-se que nenhum aluno indicou sentir-se menos motivado.

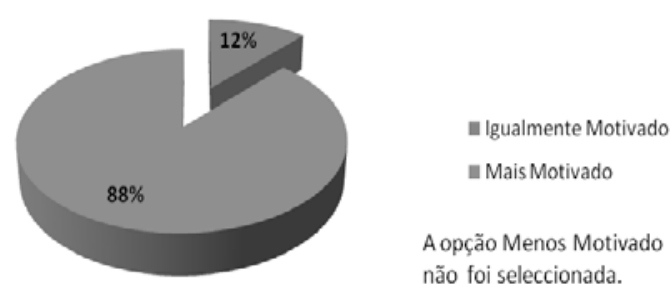

Imagem 4. Motivação dos alunos nas aulas com atividades multimédia.

A satisfação dos alunos está bem patente nos registos do diário. Logo no final da primeira sessão vários alunos bateram palmas no final da realização da atividade, imitando o jogo e demonstrando a sua euforia e satisfação por conseguir concluir com sucesso. Outro exemplo deste estado de espírito foram as expressões utilizadas por alguns alunos, tais como: “yes”, “tive tudo certo no primeiro jogo”, “já vou no 7”, “é fácil”, “já vou no último”, “já acabei”. Noutra sessão, já no final da aula, mesmo depois do toque de saída, os alunos quiseram acabar o jogo, recusando-se a sair mais para o almoço. Das doze sessões assistidas o interesse pelas atividades foi bem patente, melhorando, segundo os professores as predisposição para a aprendizagem. É também de referir que as manifestações de euforia pela utilização das atividades multimédia no computador Magalhães foram mais evidentes nos alunos dos primeiros anos de escolaridade. Isto talvez tenha acontecido pelo facto do computador com atividades interativas na sala de aula ser completa novidade.

- Verificar a autonomia dos professores na utilização do computador Magalhães

Umas das problemáticas da integração curricular das TIC é a autónoma dos professores para esse desígnio. Para desenvolverem as competências necessárias os professores necessitam de estra conscientes das vantagens dessa integração. Essa consciência parece ter sido desenvolvida pelos professores, como podemos verificar em entrevista:

"[O computador] simplifica a nossa vida e simplifica também a própria aprendizagem dos alunos, porque eles sentem-se mais motivados e procuram com mais interesse, não dispersando as suas ideias, não de distraindo, portanto, conseguindo concentrar-se e estar atentos à matéria que estamos a fazer. Participam mais. Nota-se muita diferença, os alunos que numa aula normal, oral, com quadro preto não participam, estão a ouvir, muitas vezes não procuram, não tiram dificuldades, no Computador Magalhães, ao utilizá-lo, muitas vezes procuram, querem saber porquê e motivam-se eles próprios, portanto, é uma mais-valia para todos os efeitos”. Outro aspeto a ressalvar é a valorização profissional que os professores sentem por verem o seu trabalho reconhecido pelos alunos: "Acho que até valorizou a imagem que os nossos alunos tinham de nós, porque houve um que me disse: - está cá o seu nome professora! Eu disse: - pois está, fui eu que o fiz! Ao que o aluno interrogou: - foi? Acho que o miúdo ficou a apreciar-me de outra maneira, a ver que a professora era capaz de criar um jogo de computador. Dá-me a impressão que aos olhos dos alunos, eu fiquei valorizada.

Nenhum professor indicou encontrar desvantagens na utilização das TIC na sala de aula, o fato de não utilizarem as TIC anteriormente prendia-se essencialmente com a falta de tempo, motivação e conhecimentos para trabalhar com o Computador. No entanto, após o Projeto, todos indicaram que as suas práticas educativas mudaram e serão diferentes doravante. O primeiro passo para a integração das TIC é o reconhecimento dessa necessidade. Esse reconhecimento ficou bem evidente na entrevista de um professor: "Hoje o computador é o giz. O professor sem giz, mesmo que tenha o quadro, não faz nada, e hoje um professor sem computador nada faz", ou como referia outro: "Um professor sem computador é um professor manco".

\section{Reflexão final}

Tendo o país feito o esforço financeiro, através do PTE, para apetrechar as escolas com infraestruturas tecnologias e o fornecimento de um computador a cada aluno, parece-nos natural que todos esses recursos não devem ficar desaproveitados nem devem ser utilizados como instrumentos para reforçar práticas pedagógicas tradicionais. A sua rentabilização, quanto a nós, passa por utilizar esses recursos visando a mudança de 
práticas educativas, ou seja, os professores devem ser capazes de inovar nas práticas colocando os novos recursos ao serviço de novas formas de aprender. Foi neste sentido que nos propusemos desenvolver este projecto, procurando contribuir para que, pelo menos os professores que estão a participar, passem professores inovadores com TIC. Partimos de um contexto pouco favorável à integração do computador em sala de aula visando a aprendizagem de conteúdos disciplinares. Verificamos que alguns dos professores participantes tiveram dificuldades na elaboração dos seus próprios matérias digitais utilizando o Edilim. Contudo todos conseguiram realizar essa tarefa desenvolvendo livros digitais para diferentes temáticas. Em relação à utilização das atividades educativas em Edilim com recursos ao computador Magalhães, verificamos que os alunos possuem uma predisposição natural na utilização do computador e as pequenas dúvidas que surgem na resolução de atividades educativas, manifestavam-se mais no início e rapidamente foram ultrapassadas. A motivação e o interesse e a predisposição para a aprendizagem aumentou bastante nas aulas onde se utilizaram os recursos digitais. Este tipo de experiência foi nova para os professores participantes. No final todos reconheceram as vantagens da utilização do computador nas práticas educativas do $1^{\circ}$ Ciclo e sua importância na transformação das práticas.

\section{Referencias}

Berracoso, J. V.; Arroyo, M. e Díaz, M. (2010). Políticas educativas para la integración de las TIC en Extremadura y sus efectos sobre la innovación didáctica y el proceso enseñanza-aprendizaje: la percepción del profesorado1. Revista de Educación, 352. Mayo-Agosto 2010, pp. 99-124 http://www.umic.pt/images/stories/publicacoes2/A_S I_em_PT_doc_trabalho_Maio_2010.pdf
EURYDICE (2011). Key data on learning and innovationthrough ICT at School in Europe. Bruselas, Eurydice. Acedido em 04/09/2013. Disponível em: http://eacea.ec.europa.eu/education/eurydice/docume nts/key_data_series/129EN_HI.pdf

Ministério da Educação (2009. Plano tecnológico da educação. Acedido em 27/4/2011. Disponível em: http://www.eb23-agueda.rcts.pt/pte/pte.pdf

Pedró, F. (2010). A necessidade de uma abordagem sistémica. In: OCDE (2010) Inspirados pela tecnologia, norteados pela pedagogia. Acedido a 22/11/2011, disponível em: http://www.oecd.org/dataoecd/14/39/47785311.pdf

PORTUGAL (1997). Livro verde para a Sociedade da Informação em Portugal Acedido em 12/9/2010. Disponível http://www2.ufp.pt/ lmbg/formacao/lvfinal.pdf

UMIC (2010). Sociedade da Informação em Portugal. Acedido em 27/4/2011. Disponível em: http://www.acesso.umic.pt/docs/livroverde_rtf.zip. 